\title{
Purchases of medical therapy recommended for coronary artery disease before and after elective revascularisation
}

\author{
Jari Heiskanen ${ }^{1,2,3}$ • Juha Hartikainen ${ }^{1,4}$ • Janne Martikainen ${ }^{3} \cdot$ Heikki Miettinen ${ }^{1} \cdot$ Mikko Hippeläinen $^{1}$. \\ Risto P. Roine ${ }^{2,5,6,7} \cdot$ Anna-Maija Tolppanen ${ }^{2,3}$ (I)
}

Received: 22 February 2019 / Accepted: 5 August 2019 / Published online: 11 October 2019

(C) The Author(s) 2019

\begin{abstract}
Aims We studied the purchases of medical therapy recommended for coronary artery disease patients before and after elective revascularisation (percutaneous coronary intervention $(\mathrm{PCI})$ or coronary bypass grafting $(\mathrm{CABG})$ ).

Methods All patients who underwent an elective PCI $(N=1557)$ or CABG $(N=1768)$ at the Heart Center, Kuopio University hospital between 2007 and 2014 were included. Data were collected from the hospital's coronary register and national registers, and obtained for 3 years before and 1 year after the revascularisation.

Results Altogether $85.2 \%$ of PCI patients and $88.1 \%$ of CABG patients had purchased lipid-modifying agents before the procedure, and $94.9 \%$ and $96.8 \%$ during the post-procedure follow-up year, respectively. Betablocking agents were purchased by $84.9 \%$ of PCI patients before and by $87.9 \%$ after the procedure and by $86.3 \%$ of CABG patients before and $97.1 \%$ after the operation. Of PCI patients, $64.3 \%$ had purchased organic long-acting nitrates before the procedure and $54.4 \%$ also after the procedure. Among CABG patients, the purchase of organic long-acting nitrates fell from $59.7 \%$ before to $10.1 \%$ after the operation. The use of ADP receptor blocking agents increased in PCI patients (26.3 to 83.9\%) and the use of warfarin in CABG patients (9.4 to $21.3 \%$ ). Medication purchases were more common among those who had greater use of hospital services before and after the procedures.

Conclusions In both PCI and CABG patients, the use of medical therapy before and after revascularisation procedure complied with current guidelines. Purchases of long-acting nitrates were common in the PCI group even after the procedure.
\end{abstract}

Keywords Evidence-based medicine $\cdot$ Public health $\cdot$ Medical research $\cdot$ Healthcare $\cdot$ Coronary disease $\cdot$ Revascularisation Optimal medical therapy

Electronic supplementary material The online version of this article (https://doi.org/10.1007/s00228-019-02735-9) contains supplementary material, which is available to authorized users.

Anna-Maija Tolppanen

anna-maija.tolppanen@uef.fi

1 Heart Center, Kuopio University Hospital, Kuopio, Finland

2 Research Centre for Comparative Effectiveness and Patient Safety (RECEPS), University of Eastern Finland, Kuopio, Finland

3 School of Pharmacy, University of Eastern Finland, P.O. Box 1627, Yliopistonranta 1 C, FI-70211 Kuopio, Finland

4 School of Medicine, University of Eastern Finland, Kuopio, Finland

5 Department of Health and Social Management, University of Eastern Finland, Kuopio, Finland

6 Kuopio University hospital, Kuopio, Finland

7 Helsinki University Hospital, Helsinki, Finland

\section{Introduction}

Optimal medical therapy (OMT) is essential for symptom control, as well as for primary and secondary prevention of coronary artery disease (CAD). Event prevention in CAD consists of acetylsalicylic acid (ASA), lipid-lowering agents and beta-blockers. In addition, angiotensin-converting enzyme (ACE) inhibitors or angiotensin receptor blocking (ARB) agents are often indicated for patients with coexisting hypertension, left ventricular ejection fraction (LVEF) $\leq 40 \%$, diabetes or chronic kidney disease. A combination of ASA and adenosine diphosphate (ADP) receptor inhibitors is used in those with acute coronary syndrome and in those undergoing elective percutaneous coronary intervention (PCI). In addition, nitrates are the cornerstone of symptom relief in angina pectoris [1-8]. 
The recommendations on postoperative OMT in patients with stable CAD are similar after percutaneous coronary intervention (PCI) or coronary artery bypass grafting (CABG), with one exception. ADP inhibitor (clopidogrel, prasugrel and ticagrelor) and ASA combination is used for the first year after percutaneous coronary intervention (PCI) but not after CABG [1, 4-8]. Otherwise, if there are no contraindications, the OMT should continue as a lifelong secondary prevention therapy after the revascularisation procedure [6-8].

Secondary prevention and drug adherence are essential for the development of effective critical pathways and prevention of future cardiovascular events in patients undergoing revascularisation. According to earlier research [9-13], the overall adherence to secondary prevention measures tendsed to improve regardless of revascularisation type, although there was still room for improvement. According to a recent Danish study [14], there was an increasing trend in drug use for primary prevention in the first decade of the twenty-first century.

The aims of this study were to compare the use of medical therapy recommended for coronary artery disease patients before and after an elective revascularisation procedure and to assess temporal trends and factors associated with the use of OMT.

\section{Methods}

\section{Patients}

The Coronary Artery TreatmentS (CATS) study includes all CAD patients who underwent an elective revascularisation procedure at the Heart Center, Kuopio University hospital (KUH) between 2007 and 2014 ( $N=1768$ CABG, $N=1557$ PCI). The functional clinical status of the patients was assessed by the New York Heart Association (NYHA) $[15,16]$ and the Canadian Cardiovascular Society (CCS) grading system [17-20].

\section{Data linkage and registers}

The clinical data from the hospital revascularisation registers were linked to national registers with personal identification numbers. Data on mortality were obtained from the Statistic Finland [21]. The Care Register for Health Care covers, as mandated by law, all inpatient hospital admissions.

The National Prescription Register contains information on all reimbursed prescription medication purchased by the patients. Information about medications dispensed in the non-community settings (hospital, public nursing homes) was not available from the register. Drugs are classified according to the Anatomical Therapeutic Chemical (ATC) classification system.

Use of cardiovascular medication was identified as any ATC code C. These drugs were further classified into cardiac therapy drugs ( $\mathrm{C} 01)$ and combinations. OMT drugs were categorised more precisely as follows: Nitrates (C01DA) were divided by medicine form into short-acting nitrates (C01DA02: sublingual nitroglycerin and C01DA08: oral spray) and long-acting nitrates (C01DA02: transdermal patch, ointments; C01DA08: tablets; C01DA14: tablets). Antihypertensives (C02, $\mathrm{C} 07 \mathrm{~F})$ included diuretics $(\mathrm{C} 03, \mathrm{C} 02 \mathrm{~L}, \mathrm{C} 07 \mathrm{~B}, \mathrm{C} 07 \mathrm{C}$, C07D, C08G, C09DA, C09DX01, C09DX03, C09BX01); beta-blockers (C07, C09BX02); calcium channel blockers (C08, C07F, C09BB, C09DB, C09BX01, C09DX01, C10BX03); agents acting on the renin-angiotensin system (C09), such as ACE inhibitors (C09A, C09B); and angiotensin II antagonists (C09C, C09D, C09DX03). Lipid-lowering drugs were identified by code (C10). ADP inhibitors were identified as platelet aggregation inhibitors excluding heparin (B01AC) and more specific ATC codes for clopidogrel (B01AC04), prasugrel (B01AC22) and ticagrelor (B01AC24) were used. In addition, a minor proportion of ADP inhibitor purchases consisted of ticlopidine (B01AC05). Other antiaggregatory agents listed were acetylsalicylic acid B01AC06, dipyridamole B01AC07 and combinations $\mathrm{B} 01 \mathrm{AC} 30$.

\section{Statistical analyses}

The proportion of users in each medication group was calculated from the eligible population (community dweller and alive) 3 years before and 1 year after the procedure. All statistical analyses were conducted by STATA14.0 (Stata Corp LP, Station, TX, USA).

Exact McNemar's test to assess the statistical significance of differences on dichotomous dependent variables between two related groups was used for analysing differences in purchase proportions before and after the procedure for both the PCI and CABG groups. Logistic regression models were used to analyse overall cardiovascular medication purchases. Independent variables in regression models were age, sex, operation year, hospitalisation during follow-up time and disease severity (NYHA/CCS class).

Persons with missing CCS/NYHA data (PCI group $n=40$ ) were excluded from logistic regression analyses. There were no other missing data. Those who died during the follow-up (PCI group $n=39$ ) and (CABG group $n=28$ ) were excluded. 


\section{Standard protocol approvals, registrations and patient consents}

The study was approved by the ethics committee of Kuopio University hospital (KUH) and by the ethics committee of the Finnish National Institute for Health and Welfare which gives the permissions to use the data from the Hospital Discharge Register (HILMO). The permission to use the Special Reimbursement and Prescription registers was given by the Social Insurance Institution of Finland (SII). The permission to use national mortality data was given by Statistics Finland. Informed consent was not deemed necessary by the Ethics committees or register maintainers because participants were not contacted. The study complies with the Declaration of Helsinki.

\section{Results}

\section{Patient characteristics}

During the study period (2007-2014) elective PCI was performed in 1557 patients and elective CABG in 1768 patients. The mean age of PCI patients was 67.1 years and that of CABG patients 66.3 years. Majority of patients $(70.8 \%$ of PCI and $80.1 \%$ of CABG patients) were men. CABG patients had more severe symptoms as indicated by CCS/NYHA class (Table 1).

All-cause mortality rates during the one-year follow-up were $2.7 \%$ and $1.7 \%$ for PCI and CABG, respectively. Three $(0.2 \%) \mathrm{PCI}$ and two $(0.1 \%)$ CABG patients died during the revascularisation procedure.

The median numbers of hospital inpatient days before the revascularisation were 7 (range 0-655) and 7 (range $0-355)$ in the PCI and CABG groups, respectively. A total of $131(8.4 \%)$ PCI and $13(0.7 \%)$ CABG patients did not have any inpatient admissions during the 3 years before the operation. Majority of both CABG (53.4\%) and PCI $(65.4 \%)$ patients had 1-10 inpatient days before the procedure (Table 1).

The median numbers of inpatient admissions within 1 year after the revascularisation were 3 (range $0-193$ ) and 3 (range $0-164)$ in the PCI and CABG groups, respectively. A total of 279 (17.9\%) PCI and 163 (9.2\%) CABG patients did not have any inpatient admissions during the one-year follow-up after the procedure. Majority of PCI patients (71.4\%) and CABG patients $(65.4 \%)$ had $1-10$ inpatient days after the intervention (Table 1).

\section{Purchases of recommended medical therapy}

A total of 1519 (97.6\%) PCI and 1690 (95.6\%) CABG patients had purchased any cardiovascular drugs within the three-year timeframe before the intervention (Table 2). Correspondingly, nearly all patients $(99.3 \%$ of PCI patients $(n=1546)$ and $98.4 \%$ of CABG patients $(n=1740))$ had purchased cardiovascular drugs within 1 year after the intervention.

The most commonly purchased drug classes before the operation were lipid-modifying agents, beta-blocking agents and nitrates (Table 2). Purchases of lipid-modifying agents and beta-blockers increased after the operation among both PCI $(p<0.001)$ and CABG $(p<0.001)$ patients (Table 2$)$. Long-acting nitrates were purchased before the operation by $64.3 \%$ of PCI patients and $59.7 \%$ of CABG patients $(p=\mathrm{NS})$. However, after the operation, the purchase of long-acting nitrates changed differently in PCI and CABG patients: It decreased in PCI patients (to $54.4 \%, p<0.001$ ) and much more in CABG patients (to $10.1 \%, p<0.001$ ) (Table 2). Agents acting on the renin-angiotensin system (ACE inhibitors and angiotensin II receptor antagonists) were purchased more often in the PCI group $(p<0.001)$ after the intervention (Table 2).

Table 1 Study population

\begin{tabular}{lcc}
\hline & PCI $(N=1557)$ & CABG $(N=1768)$ \\
\hline Age mean, 95\% CI & $67.1(66.6-67.6)$ & $66.3(65.9-66.7)$ \\
Men, $n$ (\%) & $1102(70.8)$ & $1416(80.1)$ \\
CCS/NYHA class & & $4(0.2)$ \\
0 & $44(2.8)$ & $47(2.7)$ \\
1 & $103(6.6)$ & $553(31.3)$ \\
2 & $694(44.6)$ & $900(50.9)$ \\
3 & $510(32.8)$ & $263(14.9)$ \\
4 & $166(10.7)$ & 0 \\
Missing CCS/NYHA & $40(2.6)$ & $2(0.1)$ \\
Died during procedure & $3(0.2)$ & $28(1.6)$ \\
Died within 12 months after the procedure & $39(2.6)$ & \\
\hline
\end{tabular}




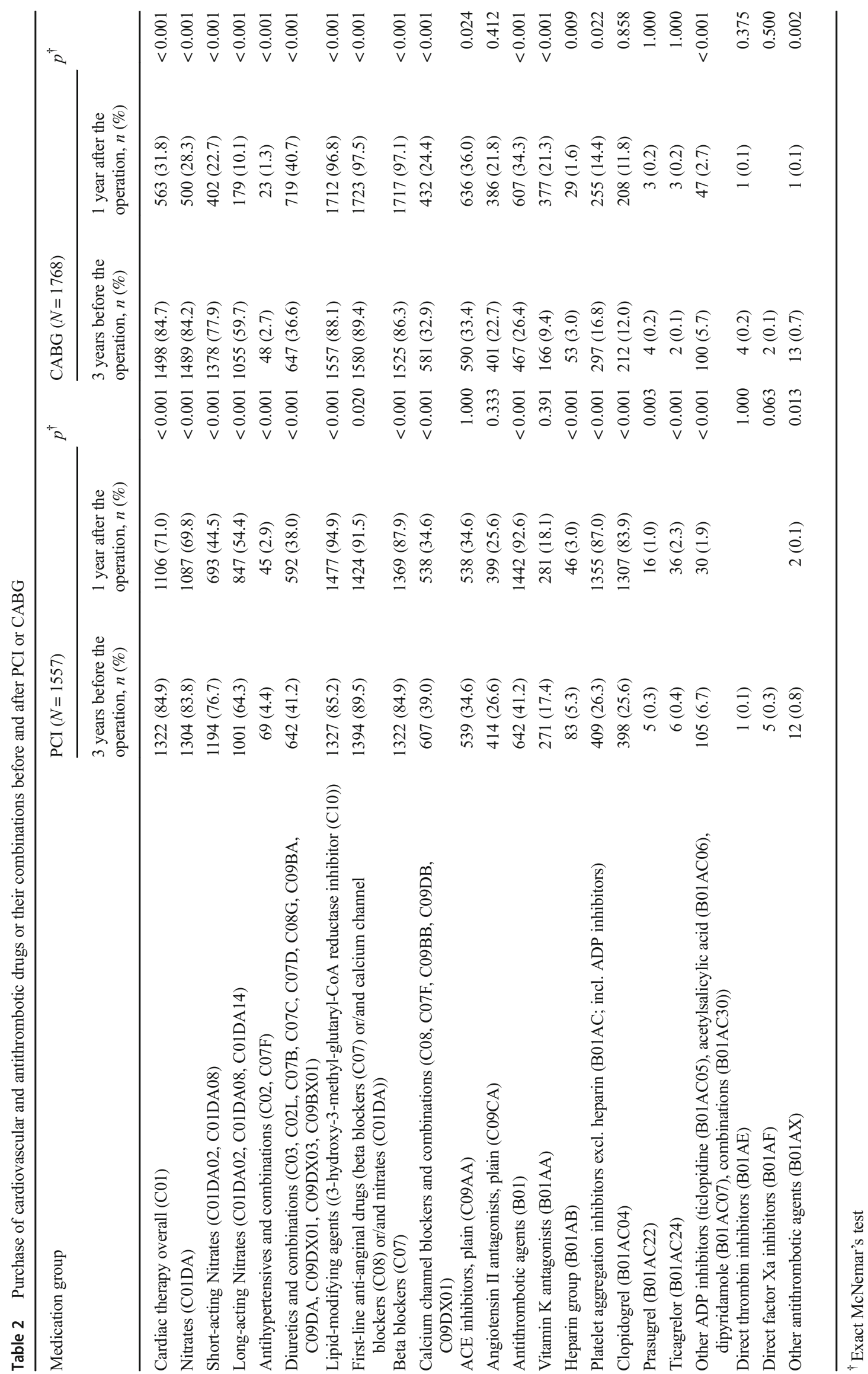


Purchases of calcium channel blockers decreased after both types of intervention $(p<0.001)$. Diuretics purchases decreased moderately in the PCI group $(p<0.001)$ but increased moderately in the CABG group $(p<0.001)$. Other antihypertensive drug purchases were rare in both groups (Table 2 and Supplementary Table 1).

The purchase of ADP inhibitors increased among PCI patients $(p<0.001)$ but decreased among CABG patients $(p=0.022)$. On the other hand, the purchase of vitamin $\mathrm{K}$ antagonists (VKA) increases after CABG $(p<0.001)$.

\section{Predictors of purchases}

Older persons and those with more severe disease, indicated by previous hospital stays or higher CCS/NYHA class, had more often purchased cardiovascular drugs before PCI (Table 3). The association between drug purchases and previous hospital stays was also observed when assessing the predictors of purchase after PCI. However, CCS/NYHA class was not associated with cardiovascular drug purchases after PCI, and the association of age was reversed, i.e. older patients were less likely to buy drugs. Intervention year was not associated with cardiovascular drug purchases before or after PCI (Table 3).

Older persons had more often purchased cardiovascular drugs before CABG (Table 4). Those with the most severe disease, indicated by CCS/NYHA class 4 , had very low drug purchase activity. Also the intervention year was associated with lower cardiovascular drug purchases before CABG during the years 2009 and 2010 (Table 4). The association between drug purchases and age was reversed, i.e. older patients were less likely to buy drugs after CABG (Table 4). However, CCS/NYHA class was not associated with cardiovascular drug purchases after PCI or CABG.

\section{Discussion}

The main finding of our study was that the use of medical therapy recommended for coronary artery disease evaluated on the basis of purchased drugs before and after revascularisation was in line with the European and Finnish guidelines and recommendations [1-7]. Almost all patients used recommended coronary artery disease drugs during the follow-up time (3 years before and 1 year after the elective PCI or CABG). The decrease in nitrate purchases, especially long-acting nitrates, suggests that the revascularisation procedure was in most cases considered successful in alleviating the $\mathrm{CAD}$ symptoms. The reasons for the higher percentage of patients having bought long-acting nitrates after PCI (54\%) cannot be evaluated with our data. However, in earlier randomised studies comparing PCI and CABG, the need for repeat revascularisation has been higher among PCI-treated patients [22]. Thus, it is possible that PCI-treated patients have more angina symptoms after revascularisation than $\mathrm{CABG}$-treated patients.

Another difference between PCI and CABG patients was seen in the purchase of ADP receptor blocking agents. They were more commonly used after PCI: Their purchase increased from 26.3 (pre-intervention) to $87.0 \%$ (post-intervention). The most commonly used antithrombotic agent was clopidogrel which was used by $25.6 \%$ of PCI patients before

Table 3 Associations of overall cardiovascular therapy drug $(\mathrm{C})$ purchase three years before and one year after PCI procedure with clinical parameters

\begin{tabular}{|c|c|c|c|c|c|c|c|c|c|c|c|}
\hline \multirow{2}{*}{\multicolumn{2}{|c|}{$\begin{array}{l}\text { Dependent variable overall } \\
\text { cardiovascular therapy drug (C) } \\
\text { purchase }^{\dagger}\end{array}$}} & \multicolumn{4}{|c|}{ Before procedure } & \multirow[t]{3}{*}{$p$} & \multicolumn{4}{|c|}{ After procedure } & \multirow[t]{3}{*}{$p$} \\
\hline & & \multicolumn{2}{|c|}{ Drug (C) purchase } & \multirow[t]{2}{*}{ OR } & \multirow[t]{2}{*}{$95 \% \mathrm{CI}$} & & \multicolumn{2}{|c|}{ Drug $(\mathrm{C})$ purchase } & \multirow[t]{2}{*}{ OR } & \multirow[t]{2}{*}{$95 \% \mathrm{CI}$} & \\
\hline & & Yes, $n(\%)$ & No, $n(\%)$ & & & & Yes, $n(\%)$ & No, $n(\%)$ & & & \\
\hline \multicolumn{2}{|l|}{ Mean age } & $\begin{array}{l}67.3 \\
1519(97.6)\end{array}$ & $\begin{array}{l}61.3 \\
38(2.4)\end{array}$ & 1.05 & $1.02-1.09$ & 0.004 & $\begin{array}{l}67.1 \\
1546(99.3)\end{array}$ & $\begin{array}{l}75.0 \\
11(0.7)\end{array}$ & 0.89 & $0.82-0.97$ & 0.008 \\
\hline \multirow[t]{2}{*}{ Sex } & Men & $1074(70.7)$ & $28(73.7)$ & 1.00 & Reference & & $1094(70.8)$ & $8(72.7)$ & & & \\
\hline & Women & $445(29.3)$ & $10(26.3)$ & 0.70 & $0.32-1.56$ & 0.388 & $452(29.2)$ & $3(27.3)$ & 1.72 & $0.41-7.29$ & 0.461 \\
\hline \multirow[t]{2}{*}{ Hospitalisation } & No & $25(65.8)$ & $13(34.2)$ & 1.00 & Reference & & $127(8.2)$ & $4(36.4)$ & & & \\
\hline & Yes & $1401(92.2)$ & $118(7.8)$ & 6.70 & $3.12-14.37$ & $<0.001$ & $1419(91.8)$ & $7(63.6)$ & 11.1 & $2.89-42.84$ & $<0.001$ \\
\hline \multirow[t]{4}{*}{ CCS/NYHA class } & 1 & $138(9.3)$ & $9(24.3)$ & 1.00 & Reference & & $147(9.8)$ & $\mathrm{n} / \mathrm{a}$ & 1.00 & & \\
\hline & 2 & $680(46.0)$ & $14(37.8)$ & 3.42 & $1.40-8.39$ & 0.007 & $690(45.8)$ & $4(36.4)$ & 1.00 & Reference & \\
\hline & 3 & $506(34.2)$ & $4(10.8)$ & 6.97 & $2.00-24.26$ & 0.002 & $505(33.5)$ & $5(45.5)$ & 0.64 & $0.15-2.74$ & 0.550 \\
\hline & 4 & $156(10.5)$ & $10(27.0)$ & 0.82 & $0.31-2.18$ & 0.690 & $164(10.9)$ & $2(18.2)$ & 0.45 & $0.07-2.72$ & 0.383 \\
\hline
\end{tabular}

${ }^{\dagger}$ Independent variables: mean age, sex, hospitalisation, operation year, CCS class 


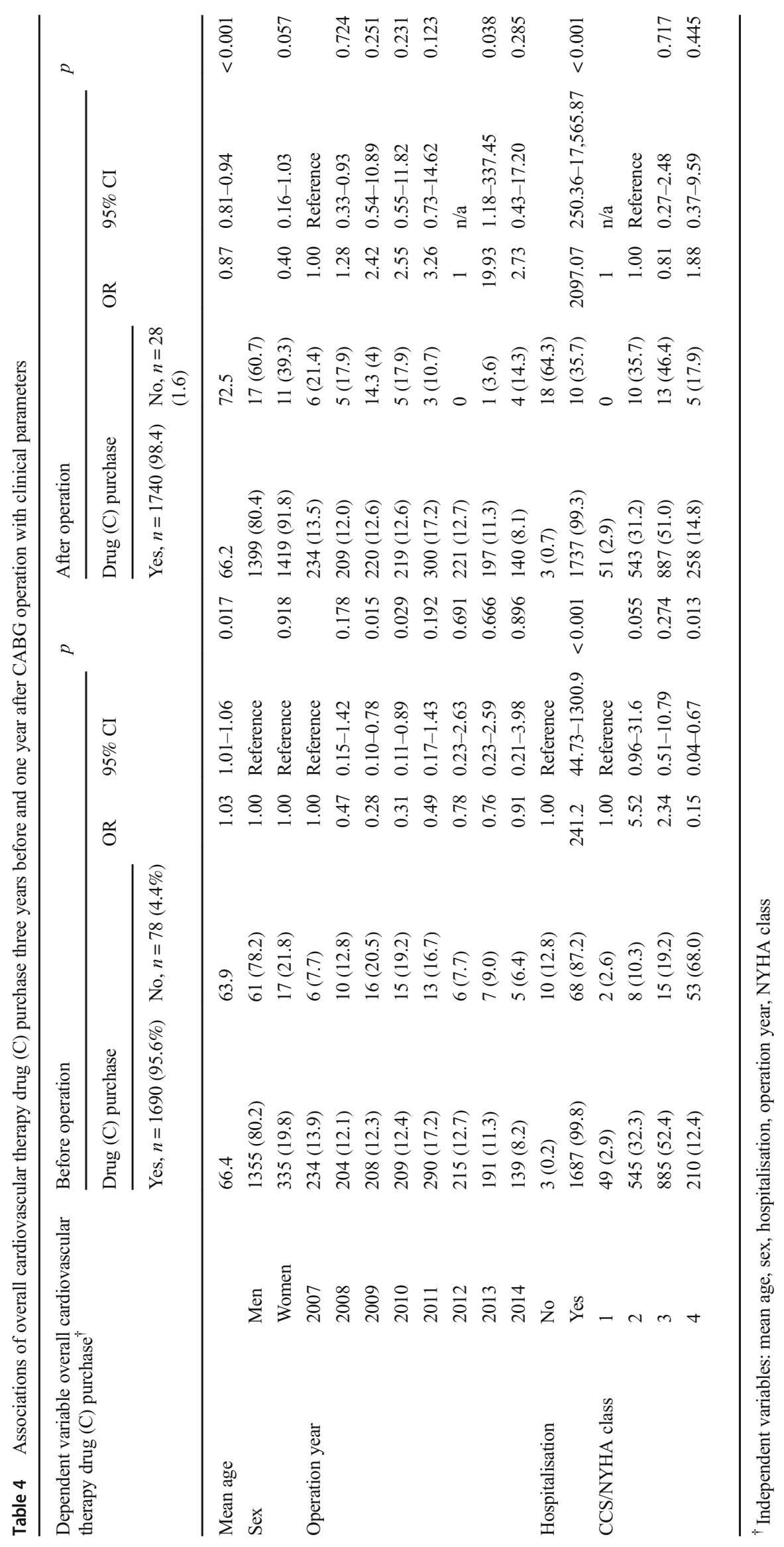


and by $83.9 \%$ after the PCI procedure. In CABG patients, the use of ADP receptor blockers was less prevalent: Only $16.8 \%$ of CABG patients had purchased them before and $14.4 \%$ after the operation. The difference between PCI and CABG patients was to be expected as guidelines recommend the use of ADP receptor antagonists and ASA combination after PCI whereas after $\mathrm{CABG}$ only in patients with acute coronary syndrome. In patients undergoing elective CABG, only ASA is usually recommended. On the other hand, the use of VKA more than doubled after CABG. Most likely, the indication for VKA was postoperative atrial fibrillation. Postoperative atrial fibrillation develops in 20-30\% of patients after CABG, which is in line with the purchase of VKA in our CABG patients (21.3\%).

One important reason for the low use of antithrombotic agents after $\mathrm{CABG}$ can be that those patients are prescribed ASA drugs, which in Finland are non-reimbursable over the counter drugs for both cardiovascular and analgesic indications. Consequently, they are not recorded in the prescription register, except for a few special cases in which they had been purchased based on a prescription.

A major strength of our study is the representative study population. We identified all eligible patients from the electronic medical records, and the proportion of missing data on patient characteristics was small. The number of persons that were lost to follow-up was small and likely had no effect on the results or conclusions. Possible risk for bias was the validity of register data. The validity of the data from the national registers has been established earlier [23]. Kuopio University hospital is the only university hospital in its catchment area and performs all surgical revascularisations in the area. Thus, the patients were not selected on any basis.

A potential weakness of the study is that we only studied one of the five catchment areas performing coronary revascularisation procedures in Finland and the drug prescribing habits may be different in other regions. This limits the generalisation of purchase habits regarding single medications. We had no information on the setting where the medications were prescribed and lacked data on dosage, dose titration and adherence or compliance on a patient level. However, we had data on purchased medications instead of mere prescriptions.

In conclusion, our study demonstrates that physicians treating revascularisation patients prescribe the recommended medical therapy according to current guidelines and that the patient compliance, at least during the first year after the revascularisation procedure, is high.

Author contributions AMT, RPR, JHA, HMI, MHI and JMA contributed to the conception or design of the work. JHE and AMT contributed to the acquisition and analysis. All contributed to the interpretation of data for the work. JHE drafted the manuscript. AMT, RPR, JHA, HMI, MHI and JMA critically revised the manuscript. All gave final approval and agree to be accountable for all aspects of work ensuring integrity and accuracy.
Funding Open access funding provided by University of Eastern Finland (UEF) including Kuopio University Hospital. RPR acknowledges financial support by European Structural Funds, European Social Fund by the Regional Council of North Savo and State Research Funding (VTR). AMT acknowledges support from the Academy of Finland (grants 307232 and 295334) and University of Eastern Finland. JHA acknowledges financial support from European Union FP7 and EU Horizon 2020 frameworks, Finnish Cardiovascular Research Foundation and State Research Funding (VTR). The funders had no role in study design, data collection or analysis, decision to publish or preparation of the manuscript. The views expressed in this paper are those of the authors and not necessarily those of any funding body or others whose support is acknowledged.

Compliance with ethical standards The study was approved by the ethics committee of Kuopio University hospital (KUH) and by the ethics committee of the Finnish National Institute for Health and Welfare which gives the permissions to use the data from the Hospital Discharge Register (HILMO). The permission to use the Special Reimbursement and Prescription registers was given by the Social Insurance Institution of Finland (SII). The permission to use national mortality data was given by Statistics Finland. Informed consent was not deemed necessary by the Ethics committees or register maintainers because participants were not contacted. The study complies with the Declaration of Helsinki.

Conflict of interest JHE, AMT, RPR, JHA, MHI and HMI have nothing to disclose and declare that there is no conflict of interest. JM is a partner of ESiOR Oy, which carries out health economic and outcome research studies for pharmaceutical, medical device and food companies.

Open Access This article is licensed under a Creative Commons Attribution 4.0 International License, which permits use, sharing, adaptation, distribution and reproduction in any medium or format, as long as you give appropriate credit to the original author(s) and the source, provide a link to the Creative Commons licence, and indicate if changes were made. The images or other third party material in this article are included in the article's Creative Commons licence, unless indicated otherwise in a credit line to the material. If material is not included in the article's Creative Commons licence and your intended use is not permitted by statutory regulation or exceeds the permitted use, you will need to obtain permission directly from the copyright holder. To view a copy of this licence, visit http://creativecommons.org/licenses/by/4.0/.

\section{References}

1. Members TF, Montalescot G, Sechtem U, Achenbach S, Andreotti F, Arden C et al (2013) 2013 ESC guidelines on the management of stable coronary artery disease: the task force on the management of stable coronary artery disease of the European Society of Cardiology. Eur Heart J 34(38):2949-3003

2. Piepoli MF, Hoes AW, Agewall S, Albus C, Brotons C, Catapano AL, Cooney MT, Corrà U, Cosyns B, Deaton C, Graham I, Hall MS, Hobbs FDR, Løchen ML, Löllgen H, Marques-Vidal P, Perk J, Prescott E, Redon J, Richter DJ, Sattar N, Smulders Y, Tiberi M, van der Worp H, van Dis I, Verschuren WMM, Binno S, ESC Scientific Document Group (2016) 2016 European Guidelines on cardiovascular disease prevention in clinical practice: the Sixth Joint Task Force of the European Society of Cardiology and Other Societies on Cardiovascular Disease Prevention in Clinical Practice (constituted by representatives of 10 societies and by invited experts) developed with the special contribution of the European Association for Cardiovascular Prevention \& Rehabilitation (EACPR). Eur Heart J 37(29):2315-2381 
3. Kolh P, Windecker S, Alfonso F, Collet JP, Cremer J, Falk V, Filippatos G, Hamm C, Head SJ, Jüni P, Kappetein AP, Kastrati A, Knuuti J, Landmesser U, Laufer G, Neumann FJ, Richter DJ, Schauerte P, Sousa Uva M, Stefanini GG, Taggart DP, Torracca L, Valgimigli M, Wijns W, Witkowski A, European Society of Cardiology Committee for Practice Guidelines, Zamorano JL, Achenbach S, Baumgartner H, Bax JJ, Bueno H, Dean V, Deaton C, Erol Ç, Fagard R, Ferrari R, Hasdai D, Hoes AW, Kirchhof P, Knuuti J, Kolh P, Lancellotti P, Linhart A, Nihoyannopoulos P, Piepoli MF, Ponikowski P, Sirnes PA, Tamargo JL, Tendera M, Torbicki A, Wijns W, Windecker S, EACTS Clinical Guidelines Committee, Sousa Uva M, Achenbach S, Pepper J, Anyanwu A, Badimon L, Bauersachs J, Baumbach A, Beygui F, Bonaros N, de Carlo M, Deaton C, Dobrev D, Dunning J, Eeckhout E, Gielen S, Hasdai D, Kirchhof P, Luckraz H, Mahrholdt H, Montalescot G, Paparella D, Rastan AJ, Sanmartin M, Sergeant P, Silber S, Tamargo J, ten Berg J, Thiele H, van Geuns R, Wagner HO, Wassmann S, Wendler O, Zamorano JL, Task Force on Myocardial Revascularization of the European Society of Cardiology and the European Association for Cardio-Thoracic Surgery, European Association of Percutaneous Cardiovascular Interventions (2014) 2014 ESC/EACTS Guidelines on myocardial revascularization: the Task Force on Myocardial Revascularization of the European Society of Cardiology (ESC) and the European Association for Cardio-Thoracic Surgery (EACTS). Developed with the special contribution of the European Association of Percutaneous Cardiovascular Interventions (EAPCI). Eur J Cardiothorac Surg 46(4):517-592

4. Henderson RA, O'Flynn N, Guideline Development Group (2012) Management of stable angina: summary of NICE guidance. Heart 98(6):500-507

5. NICE (National Institute for Health and Care Excellence). Stable angina: management. 2016; Available at: https://www.nice.org.uk/ guidance/cg126/chapter/1-Guidance\#anti-anginal-drug-treatment. Accessed 04/11, 2017

6. Suomalainen Lääkäriseura Duodecim (The Finnish Medical Society Duodecim and Duodecim Medical Publications Ltd). Käypä hoito suositus: Sepelvaltimotautikohtaus (epästabiili angina pectoris ja sydäninfarkti ilman ST-nousuja) (attack of coronary artery disease: unstabile angina pectoris and myocardial infarction without ST- segment elevation - national current care guidelines). 2015; Available at: http://www.kaypahoito.fi/web/kh/potilaalle/ suositus?id=khp00029. Accessed 04/10, 2017

7. Suomalainen Lääkäriseura Duodecim (the Finnish Medical Society Duodecim and Duodecim Medical Publications Ltd). Käypä hoito suositus: Stabiili sepelvaltimotauti (stabile coronary artery disease national current care guidelines). 2015; Available at: http://www. kaypahoito.fi/web/kh/suositukset/suositus?id=hoi50102. Accessed 04/11, 2017

8. Levine GN, Bates ER, Blankenship JC, Bailey SR, Bittl JA, Cercek B, Chambers CE, Ellis SG, Guyton RA, Hollenberg SM, Khot UN, Lange RA, Mauri L, Mehran R, Moussa ID, Mukherjee D, Nallamothu BK, Ting HH (2011) 2011 ACCF/AHA/SCAI guideline for percutaneous coronary intervention: a report of the American College of Cardiology Foundation/American Heart Association Task Force on Practice Guidelines and the Society for Cardiovascular Angiography and Interventions. Circulation 124(23):e574-e651

9. Maron DJ, Boden WE, Weintraub WS, Calfas KJ, O'Rourke RA (2011) Is optimal medical therapy as used in the COURAGE trial feasible for widespread use? Curr Treat Options Cardiovasc Med 13(1):16-25

10. EUROASPIRE I and II Group, European Action on Secondary Prevention by Intervention to Reduce Events (2001) Clinical reality of coronary prevention guidelines: a comparison of EUROASPIRE I and II in nine countries. EUROASPIRE I and II group. European Action on Secondary Prevention by Intervention to Reduce Events. Lancet 357(9261):995-1001

11. Aspry K, Wu WC, Salmoirago-Blotcher E (2016) Cardiac rehabilitation in patients with established atherosclerotic vascular disease: new directions in the era of value-based healthcare. Curr Atheroscler Rep 18(2):10-016-0561-x

12. Biondi-Zoccai GG, Lotrionte M, Agostoni P, Abbate A, Fusaro M, Burzotta $\mathrm{F}$ et al (2006) A systematic review and meta-analysis on the hazards of discontinuing or not adhering to aspirin among 50, 279 patients at risk for coronary artery disease. Eur Heart J 27(22): 2667-2674

13. Kumbhani DJ, Fonarow GC, Cannon CP, Hernandez AF, Peterson ED, Peacock WF, Laskey WK, Deedwania P, Grau-Sepulveda M, Schwamm LH, Bhatt DL (2015) Temporal trends for secondary prevention measures among patients hospitalized with coronary artery disease. Am J Med 128(4):426.e1-426.e9

14. Jorgensen ME, Andersson C, Olsen AM, Juel K, Mortensen PE, Jorgensen E et al (2015) Danish trends in pharmacotherapy, comorbidities, and demographics in patients referred for coronary angiography: what changed during a decade? Eur Heart J Cardiovasc Pharmacother 1(3):157-165

15. The Criteria Committee of the New York Heart Association (1964) Nomenclature and criteria for diagnosis of diseases of the heart and blood vessels, 6th edn. Little Brown, Boston

16. The Criteria Committee of the New York Heart Association (ed) (1994) Nomenclature and criteria for the diagnosis of diseases of the heart and great vessels, 9th edn. Little Brown \& Co, Boston

17. Campeau L (1976) Letter: grading of angina pectoris. Circulation 54(3):522-523

18. Hackett TPCN (1978) Psychological aspects of rehabilitation following myocardial infarction. In: Wenger NKHH (ed) Rehabilitation of the coronary patient. Wiley, pp 243-253

19. Principal Investigators of CASS (1981) The National Heart Lung and Blood Institute Coronary Artery Surgery Study (CASS). Circulation 63(suppl I):I-1-I-80

20. Shub C, Click R, McGoon M (1996) Chapter 29: myocardial ischemia clinical syndromes; B: angina pectoris and coronary heart disease. In: Giuliani E, Bea G (eds) Mayo Clinic practice of cardiology, Third edn. Mosby, pp 1160-1190

21. Tilastokeskus (Statistics Finland). Available at: https://www.stat.fi/ til/kuol/meta_en.html. Accessed 5 Dec 2017

22. Head SJ, Davierwala PM, Serruys PW, Redwood SR, Colombo A, Mack MJ, Morice MC, Holmes DR, Feldman TE, Stahle E, Underwood P, Dawkins KD, Kappetein AP, Mohr FW (2014) Coronary artery bypass grafting vs. percutaneous coronary intervention for patients with three-vessel disease: final five-year follow-up of the SYNTAX trial. Eur Heart J 35(40):2821-2830

23. Sund R (2012) Quality of the Finnish hospital discharge register: a systematic review. Scand J Public Health 40(6):505-515

Publisher's note Springer Nature remains neutral with regard to jurisdictional claims in published maps and institutional affiliations. 